\section{Follicular Dynamic in Balady Goat in Upper Egypt Using Ultrasonography}

\author{
Ahmed M. Osman ${ }^{1}$, Hassan A. Hussein ${ }^{1}$ and Mervat S. \\ Hassan $^{2 *}$ \\ 1 Department of Theriogenology, Faculty of Veterinary \\ Medicine, Assiut University, 71515, Assiut, Egypt. \\ 2 Department of Theriogenology, Faculty of Veterinary \\ Medicine, New Valley University, New Valley, Egypt.
}

\author{
* Corresponding Author \\ Mervat S. Hassan, Department of \\ Theriogenology, Faculty of Veterinary \\ Medicine, New Valley University, New \\ Valley, Egypt. \\ Email: mervathassan1981@gmail.com \\ Submitted $9 / 11 / 2021$ \\ Accepted 10/12/2021 \\ Published 10/24/2021
}

\begin{abstract}
The objective is to study the Ultrasonographic appearances of the reproductive genitalia of cycling does ( 8 adult healthy, non-pregnant, cycling Balady does, examined daily for 6 weeks transrectal ultrasonographic examinations for two successive estrous cycles to investigate the length of cycle and as well the biometry of the ovaries, number and size of CL and follicles, size of uterus and cervix when possible). The obtained data showed that does have 3 or 4 Follicular waves. The last wave has the largest duration and the maximum follicle size (ovulatory). The characteristic features of follicular waves in does having three follicular waves denoted that the growth rates for the largest follicles of the ovulatory waves were significantly higher than first $(p<0.001)$ and second waves $(p<0.01)$. While, the characteristic features of follicular waves in doe having four follicular waves denoted that the growth rate of the largest follicles within each wave increased from the first to the fourth wave ( 0.49 to $0.85 \mathrm{~mm} /$ day respectively). The maximum diameter of the ovulatory follicles $(7.83 \pm 0.51)$ were significantly larger than the maximum diameter of the largest follicles of the other waves $(6.13 \pm 0.30$ and $5.53 \pm 0.87$ for third and first wave; $\mathrm{P}<0.05)$, and with the second wave $(5.33 \pm 0.40, \mathrm{p}<0.01)$. It is concluded that ultrasonographic examinations can be satisfactory performed in our small size local breed of Balady goats. Moreover, 3-4 follicular waves could be estimated per single cycle. However, the number of growing follicles per each wave decreased dramatically from the beginning of the wave to its end either with the anovulatory or ovulatory follicles.
\end{abstract}

Keywords: Baladi does, Follicle, Upper Egypt , Ultrasound

\section{Introduction}

The use of ultrasound in cattle reproduction made the daily monitoring of ovarian follicular development during estrous cycle possible, demonstrating the growth and regression patterns of antral follicles and allowed a clear understanding of the process of recruitment, selection and follicular dominance as mentioned by Ginther et al (1996) and Coutinho et al ( 2007).In sheep, results of transrectal ultrasound studies indicated that a wave of follicular activity occurred at the beginning and end of the estrus cycle and dominance may have occurred in association with the development of the ovulatory follicles (Evan et al, 2000 and Ali et al 2006). Kandiel et al (2011) reported that the diameter of the ovulatory follicle in goat reached its maximal diameter $(7.3 \pm 0.3 \mathrm{~mm})$ before ovulation which occurred 1-2 days after LH peak. The postovulatory wave emerged $2.20 \pm 0.37$ days post-LH peak and reached their maximal monitored diameter $(6.5 \pm 0.3 \mathrm{~mm})$ on Day 7-8. The corpus luteum (s) was detected as a roughly circumscribed hypoechoic area and attained its widest diameter $(8.37 \pm 0.35 \mathrm{~mm})$ $4.71 \pm 0.36$ days later before its regression. González et al., 1994 mentioned that the ovulatory size of follicles is $6-8 \mathrm{~mm}$, the ultrasound exams allows the small antral follicles $(2-3 \mathrm{~mm})$ to be detected as anechoic structures of sphere shape and thin wall. González et al (1999) mentioned that approximately $33 \%$ of CL have a central cavity which must not be confused with small follicles. The most important difference is the presence of typical thick wall for CL Follicular Dynamics and Follicular Waves in Cycling Doe A follicular wave is defined as the emergency or growth of one to three follicles from a pool of small follicles (2-3 $\mathrm{mm}$ in diameter) in the ovary and their growth to $\geq 5 \mathrm{~mm}$ in diameter before regression (anovulatory wave) or ovulation (ovulatory wave) (Driancourt 
2001, and Duggavathi et al 2004). Follicular waves in ewes emerge every 4-5 days both during the breeding season and during seasonal anestrum (Evan et al (2000), and Driancourt (2001) explained that in cyclic ewes, ovarian antral follicles emerge and grow from a pool of small follicles ( 2 or $3 \mathrm{~mm}$ in diameter) in a wave-like pattern, reaching diameters of $5 \mathrm{~mm}$ before regression or ovulation. Mohammadi et al (2010) showed with his work on ovarian follicular dynamics in Najdi goats, the presence of either four (n $=2$ estrus cycles) or five ( $n=3$ estrus cycles) waves of follicular growth during the inter-ovulatory interval. Each wave was characterized by the development of at least 1 large follicle (dominant) and a variable number of small follicles (subordinate). It is evident from the literature at our disposal, that cattle and buffalo received great attention, during the last few decades, on the pattern of follicular dynamics. On the other hand, sheep and especially goat require much work on this aspect of reproductive physiology for better improvement.

\section{Materials and Methods}

Eight adult healthy does were reared in a suitable stable of the Assiut Veterinary hospital, Faculty of Veterinary Medicine. Their management and nutrition were the same as those carried out in this place (table $1)$.

Table 1. Animal population used for the study.

\begin{tabular}{|c|c|}
\hline $\begin{array}{c}\text { Numbers } \\
\text { of goats }\end{array}$ & Number of waves of follicles per cycle \\
\hline $\mathrm{n}=5$ & Goats with three waves of follicles development \\
\hline $\mathrm{n}=3$ & Goats with four waves of follicles development \\
\hline
\end{tabular}

After transrectal Ultrasonographic examinations using high-resolution, real-time B-mode ultrasound equipment connected to a $7.5-\mathrm{MHz}$ transducer, these does were found to be cyclic. Ultrasonography was done with each doe after being restrained in standing position by the help of assistance. Sometimes, the Ultrasonography was performed in lying position. A small probe (7.5 MHz linear array ultrasound) was introduced into blunt small transparent, sterile plastic tubes to facilities its application within rectum, then lubricated and placed gently into the rectum, avoiding any injury and annoyance to the examined doe as possible as we can. It has an outer dimension of $10 \mathrm{~cm}$ length, $3 \mathrm{~cm}$ height and $2 \mathrm{~cm}$ width. Kaspar (1988). It is necessary for the probe to rotate laterally to explore the genitalia. Thus, the probe should be attached to stiff cable which facilitates its mobility within the rectum according to the advice of Kähn (2004).
Before the placement of the probe in the rectum digital evacuation of the rectum from the fecal matter was done, after the probe has been placed into the rectum, it is pushed cranially to find out the urinary bladder which represents the orientation point. The probe is turned a little bit laterally on both directions in order to localize the ovaries, which are situated within the curves of the uterine horns.

Does were scanned once daily for 6 weeks transrectal ultrasonographic examinations for two successive estrous cycles, and record many inter-ovulatory periods to calculate the actual length of the estrus cycle. Transrectal examination was repeated many times for each doe, to get accurate data and in rare occasions examinations were performed every 2-3 days. The first day of estrus was diagnosed by the presence of large follicles ( $\geq 5 \mathrm{~mm}$ in diameter), which grew from the pool of 2- to 3-mm follicles, was detected by ultrasonography and it was designed as a wave 1 follicle, and grow to $\geq 5 \mathrm{~mm}$ in diameter before regression or ovulation. The wave emerging every 3-5 days after the emergence of the previous follicular wave (Evans et al., 2002). The vulva and Vestibulum during estrus period is congested and the doe showed the symptoms of overt estrus (restlessness, mounting other doe and with scanty amount of mucoid viscous secretion within the vulva).

Data obtained expressed as Mean \pm MSD and subjected for statistical analysis using the student t-test and correlation between two factors according to Snedecor and Cochran (1980) and the Costat Computer Program (1986).

\section{Results}

The results of Ultrasonographic examinations were expressed in Tables (1-4), and more clearly illustrated in Figures (1\&2) and Images (1\&2). Each doe, out of the 8 does, was studied separately and their results were calculated separately with average values for all does at the end of investigation.

The follicles were detected as echo-free black circles, and the CL were detected as a gray echogenic structure with marked boundaries. The Ultrasonographic results showed follicular growth (emergence) and regression in the form of waves during each cycle with variable periods among does. The corpora lutea could be detected Ultrasonography at $\mathrm{d} 3$ post ovulation in all does. They attained an average value of $11.30 \pm 0.8 \mathrm{~mm}$ in diameter in day 9 of the cycle. Their maximum diameter reached $12.8 \mathrm{~cm}$. Their number varied between 1-3. 
The characteristic features of follicular waves in does having three follicular waves are shown in Table $2 \&$ Fig. 1. The Growth rates for the largest follicles of the ovulatory waves were significantly higher than first wave $(p<0.001)$ and second wave $(p<0.01)$. The regression rates showed a gradual increase from first to second waves with no significant differences. Meanwhile, the maximum diameters of the ovulatory follicles $(7.6 \pm 0.81)$ were significantly larger than the maximum diameter of the largest follicles of the other waves. (5.2 \pm 0.5 for first wave, $\mathrm{P}, 0.05)$ and with the second wave $(4.96 \pm 0.28, \mathrm{p}<0.01)$. Follicles growing

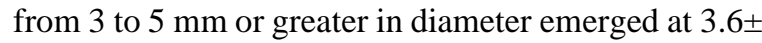
$0.54,6.6 \pm 0.54$, and $11.6 \pm 0.54$ days with a duration of $3.2 \pm 0.45,4.00 \pm 0.28$ and $5.8 \pm 0.84$, for wave 1 , wave 2 , and wave 3 respectively, in does with three waves of follicular development with a significant difference (P, 0.01-0.001) at the day of emergency.

Table 2. Showed the characters of follicular waves in Does having three Follicular waves

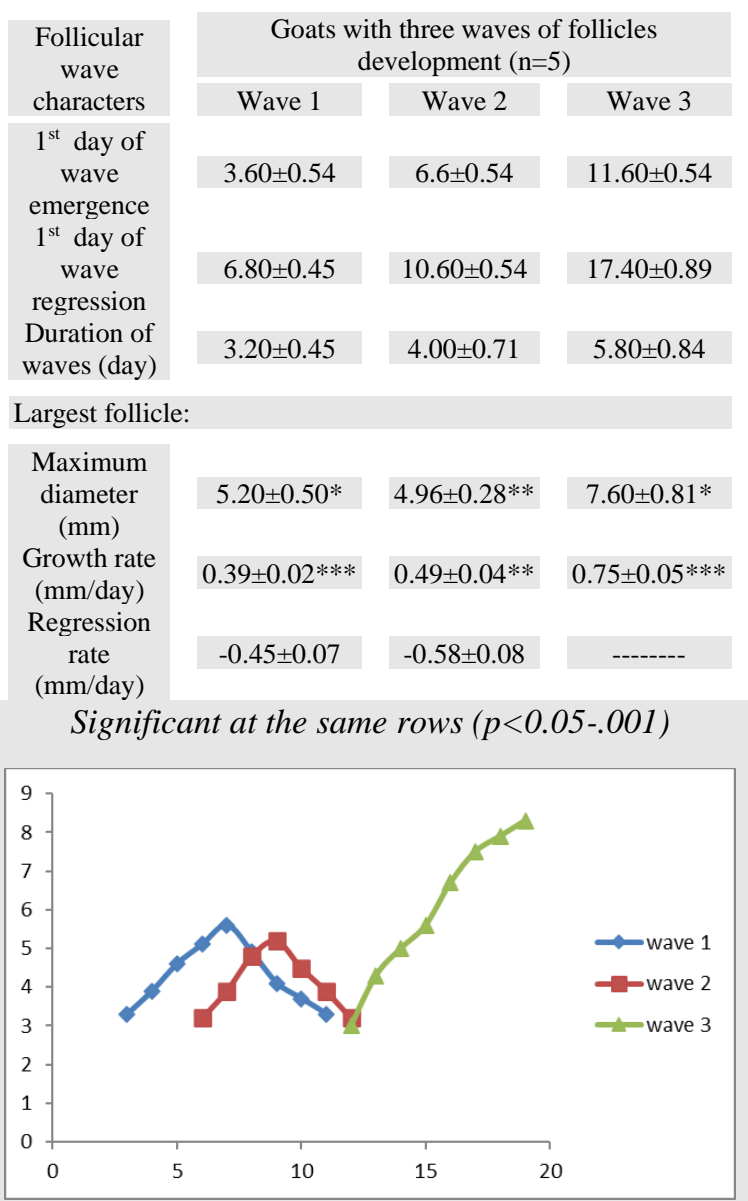

Fig. 1. Showed the Follicular diameters (mm) of the estrous cycle in Doe with three waves over the estrous cycle.
The characteristic features of follicular waves in does having four follicular waves are shown in Table $3 \&$ Fig. 2. The Growth rate of the largest follicles within each wave increased from the first to the fourth wave ( 0.49 to $0.85 \mathrm{~mm} /$ day respectively). The regression rate exhibited similar pattern of decrease in follicular size at deviation between the first and second wave ( 0.52 to $0.78 \mathrm{~mm} /$ day respectively). The maximum diameter of the ovulatory follicles $(7.83 \pm 0.51)$ were significantly larger than the maximum diameter of the largest follicles of the other waves $(6.13 \pm 0.30$ and $5.53 \pm 0.87$ for third and first wave, $\mathrm{P}, 0.05)$, and with the second wave $(5.33 \pm 0.40, \mathrm{p}<0.01)$. Follicles growing to $5 \mathrm{~mm}$ or greater in diameter emerged at $3.33 \pm 0.57,6.66 \pm 0.57,9.33 \pm 0.57$ and $12.33 \pm 0.57$ days with a duration of $3.33 \pm 0.57,3.34 \pm 0.57$, $4.33 \pm 0.57$ and $5.33 \pm 0.57$ for wave 1 , wave 2 , wave 3 and wave 4 , respectively in goats with four waves of follicular development.

Table 3. Showed the characters of follicular waves in Does having four follicular waves

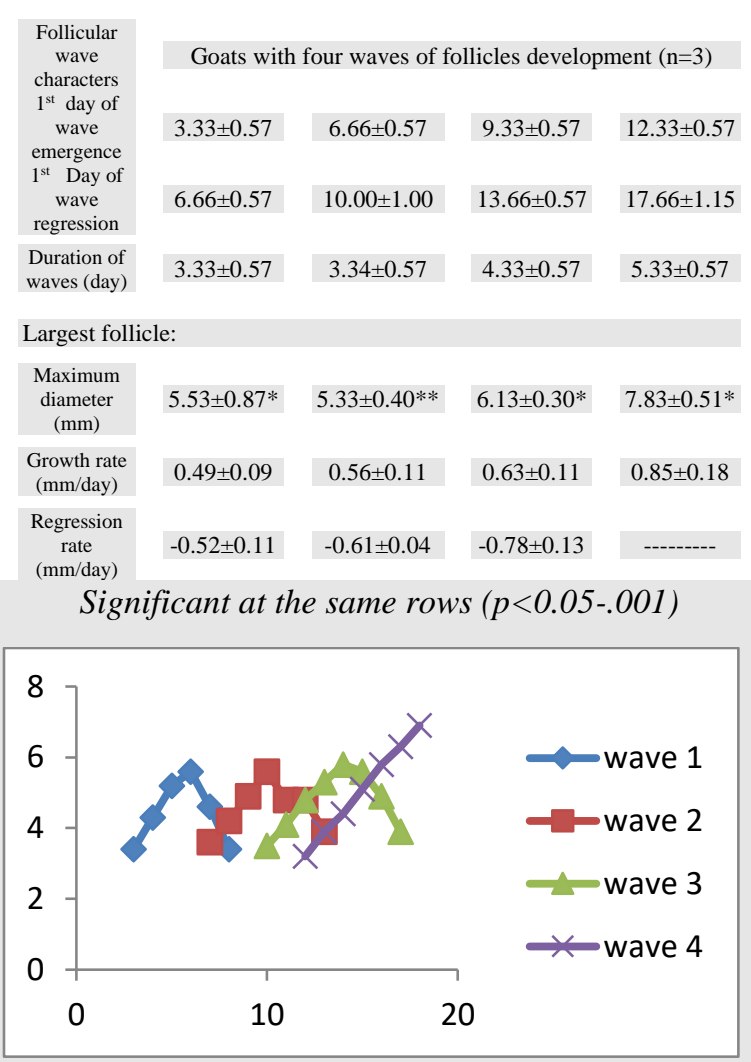

Fig. 2. Showed the Follicular diameters $(\mathrm{mm})$ of the estrous cycle in Doe with four waves over the estrous cycle.

As far as the numbers of follicles among different waves are concerned, tables 4 and 5 showed the obtained results. Out of these both tables, marked 
tendency of reduction in the numbers of follicles were noticed from the beginning of recruitment to the start of regression per each follicular waves. However, significant difference was noticed between the first wave and third wave in does having three follicular waves $(\mathrm{P}<0.05)$.

Table 4. Numbers of follicles in does having three follicular waves.

\begin{tabular}{|c|c|c|c|}
\hline $\begin{array}{l}\text { Different } \\
\text { criteria }\end{array}$ & Wave 1 & Wave 2 & Wave 3 \\
\hline $\begin{array}{l}1^{\text {st }} \text { Day of } \\
\text { wave } \\
\text { emergence }\end{array}$ & $3.8 \pm 0.83$ & $3.4 \pm 0.54$ & $2.6 \pm 0.54$ \\
\hline $\begin{array}{l}1^{\text {st }} \text { Day of } \\
\text { wave } \\
\text { regression }\end{array}$ & $3.2 \pm 0.44 *$ & $2.8 \pm 0.83$ & $1.2 \pm 0.44 *$ \\
\hline
\end{tabular}

Table 5. Number of follicles in does having four follicular waves

\begin{tabular}{cc|ccc}
\hline $\begin{array}{c}\text { Different } \\
\text { criteria }\end{array}$ & Wave 1 & Wave 2 & Wave 3 & Wave 4 \\
\hline $\begin{array}{c}\text { st } \text { Day of } \\
\text { wave } \\
\text { emergence }\end{array}$ & $3.66 \pm 1.15$ & $3.33 \pm 0.57$ & $3.00 \pm 1.00$ & $2.66 \pm 0.57$ \\
\hline $\begin{array}{c}\text { st Day of } \\
\text { wave } \\
\text { regression }\end{array}$ & $3.33 \pm 1.52$ & $2.66 \pm 0.57$ & $2.33 \pm 0.57$ & $1.66 \pm 0.57$ \\
\hline
\end{tabular}
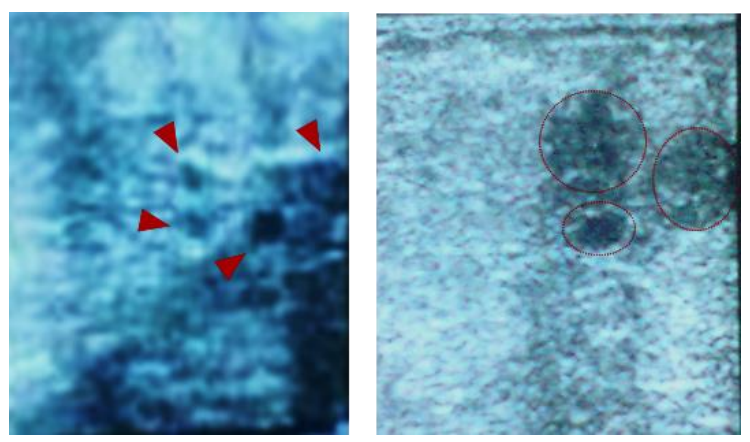

Fig. 3. Left image, Ovary containing more than one follicle. The right image, Ovary containing two corpora lutea with a follicle.

The disappearance of the largest follicle in the last follicular wave appeared to be the time of ovulation. This disappearance happened during heat. Moreover, ovulation appeared to be occurred at the end of overt estrus since the first follicular wave of the subsequent cycle started at 3-4 day from the end of heat. Moreover, the newly formed C. H. was difficult to be diagnosed by the sonar. Both ovaries were examined with the Sonar and the side which is active and has many follicular emergences was followed in the subsequent daily transrectal examinations. Meaning that, Follicular waves were followed up in either the right or left ovary according to the incidence of follicular emergency. It was noticed that the right ovary have more waves than left (5versus3respectively).

\section{Discussion}

Out of ultrasonography examination, the ovarian follicles were detected as an echo-free black circles, and the CL were detected as a gray hypoechogenic structure with marked boundaries as guided by Mohammadi et al (2010). The daily ultrasonographic examination of the studied Balady does indicate that the estrous cycles or the inter-ovulatory period is characterized by the presence of follicular wave-like pattern of development and regression (3-4 waves per cycle). This is in general agreement with previous observations reported in other breeds of goats in which the pattern of follicle development during estrous cycles followed a wave-like pattern ranged between 2 and 6 waves of follicular development during estrous cycles with 3 or 4 waves being the most prevalent (Simoes et al (2006) and Mohammadi et al (2010). Some of the factors that affect the number of waves per estrous cycle included dietary intake (Murphy et al, 1991) as well as parity and lactation status (Lucy et al, 1992). The maximum diameter of the largest ovulatory follicle of the last wave was significantly larger than those of the other waves in Balady does under investigation. (7.60 \pm 0.81 versus $5.2 \pm 0.5$ and $7.83 \pm 0.51$ versus $5.53 \pm 0.87 \mathrm{~mm}$ in does with three and four follicular waves respectively. The last follicular wave in Balady goat, which has the largest ovulatory follicle, is not differ greatly than those reported in Saanen goats (6 and $7 \mathrm{~mm}$ ) by de Castro et al (1999), in White Polish goats $(7 \mathrm{~mm})$ by Schwarz and Wierzchos (1999), in Shiba goat $(7.8 \pm 0.2 \mathrm{~mm})$; by Medan et al (2005), in Serrana goats $(6.3 \pm 1.0 \mathrm{~mm})$; by Simoes et al (2006), in Saanen goat $(6.9 \pm 1.8 \mathrm{~mm})$; by Maffili et al (2006), in Toggenburg goats (7.7 \pm 1.3 $\mathrm{mm}$ ), by Maffili et al (2006), in Najdi goats (7.75 \pm $0.83 \mathrm{~mm}$ ); by Mohammadi et al (2010) and in Zaraibi goat $(7.1 \pm 0.1 \mathrm{~mm})$ by Kandiel et al (2011).

In the present study, the mean period recorded for follicular wave from emergency until the development of dominant follicle and start of regression in the same wave reached $4.3 \pm 1.4$ day. This value is comparable to that published by Schwarz and Wierzchos (1999) in White Polish goats (4.1 \pm 0.65 days $)$.

The Corpora lutea could be identified ultrasonically in the present study at Day 3 post ovulation and attained $11.3 \pm 0.8 \mathrm{~mm}$ in day 9 with a maximum diameter of 
$12.8 \mathrm{~cm}$. These results are in agreement with the previous results of other investigators (Mohamed et al, 2003 and Simões et al , 2007) in other breeds of goat. These authors demonstrated that the first visualization of the corpus luteum in goats can be performed between Day 2 and Day 3 of estrous cycle.

The disappearance of follicular antrum of the largest follicle in the last wave of each cycle indicates the occurrence of ovulation. González et al (2004) cited that after ovulation there was an increase in the heterogeneous echogenicity in its site. The same authors explains this finding of increased heterogeneous echogenicity in its site to be due to the fact that the ultrasound structure of corpus hemorrhagicum does not differ from the rest of the ovarian parenchyma. He also added that the process of the corpus luteum formation allowed it to be clearly detected as norm and hyperechoic pattern. In Saanen goats (with three follicular waves, the number of 3$\mathrm{mm}$ follicles peaked on Days 0,7 , and 11, whereas in goats with four follicular waves, 3-mm follicles peaked on Days 1, 5, 11, and 15 (Ginther and Kot, 1994). In White Polish goats Schwarz and Wierzchos (1999) reported the days $-1,4,7,11$ and 15 for the emergence of follicles of the estrous cycle in goat with 5 follicular waves. In Bangladesh goat, Mohamed et al (2003) mentioned that follicular waves emerged at $0.3 \pm 0.5,6.5 \pm 0.2$, and $12.1 \pm 0.4$ days for wave 1 , wave 2 , and wave 3 , respectively, in goats with three waves of follicular development and at 20.6 $60.3,4.7 \pm 0.2,9.4$ \pm 0.5 , and $13.4 \pm 0.5$ days for wave 1 , wave 2 , wave 3 , and wave 4 , respectively in goat with 4 waves. Within the scope of this area, Simões et al (2006) in Serrana goats reported that the day of onset of the first, second, third and fourth wave was $1.4 \pm-1.0,6.9 \pm 1.4,11.6 \pm 1.8$ and 16.8 \pm 1.6 , respectively. No differences $(\mathrm{P}>0.05)$ were found between the day of onset of the first and second waves for estrous cycles with three, four or five waves. No differences ( $\mathrm{P}>0.05)$ were found between the day of onset of the first and second waves for estrous cycles with three, four or five waves. Mohammadi et al (2010) found in Najdi goats, that the day of follicular emergency were $-0.8 \pm 1.06,3.2 \pm 0.4$, $7.0 \pm 0.6,12.3 \pm 1.72$ and $13.0 \pm 1.63$, for the first to fifth follicular waves respectively. The present study mentioned that the growth rates for the largest follicles of the ovulatory waves were significantly higher than first wave $(p<0.001)$ and second wave $(p<0.01)$. The regression rates showed a gradual decrease from first to second waves with no significant differences especially in goat with three follicular waves. The follicular growth rates reported for the studied Balady does were $0.8 \pm 0.1,0.8 \pm 0.1,0.9 \pm 0.1,0.9 \pm 0.1 \mathrm{~mm}$ for the first, second, third and fourth wave respectively. As described by Gonzalez et al (1999); Schwarz and Wierzchos, (2000) in other breeds of goat, the ovulatory follicles increased in size at a growth rate of $1.1 \mathrm{~mm} /$ day which is higher than that happened in Balady goat. Mean values for all animals were $0.75 \pm 0.05 \mathrm{~mm}$ in does with 3 waves and $0.85 \pm 0.18$ $\mathrm{mm}$ in does with 4 waves. Moreover, the growth rate of the largest follicles within each wave increased from the first to the fourth wave $(0.49$ to $0.85 \mathrm{~mm} /$ day respectively). The regression rate exhibited similar pattern of decrease in follicular size at deviation between the first and second wave $(0.52$ to 0.78 $\mathrm{mm} /$ day respectively) in goat with four follicular waves. It seems possible that the endocrine hormones regulating the growth of the follicles (FSH and estrogen feedback mechanism) might be responsible for such findings. The length of the growing phase in the last ovulatory waves $(3.1 \pm 0.9$ days $)$ was significantly longer $(\mathrm{P}<0.001)$ than in the last anovulatory waves $(1.7 \pm 0.8$ days). Simões et al (2006) cited that the day of onset of the ovulatory wave is related to or, at least conditioned by the luteolysis of the cyclic CL's and the decrease in plasma progesterone. As far as the numbers of follicles among different waves are concerned, in Balady does during estrous cycle, marked tendency of reduction in the numbers of follicles were noticed from the beginning of each recruitment to its end at the start of each regression. However, significant reduction was noticed between the first wave and third wave in does having three follicular waves $(\mathrm{P}<0.05)$. Mohamad et al, (2003) found that the numbers of follicles per wave were $2.6 \pm 0.2 ; 2.4 \pm 0.2,2.2 \pm 0.2$ and $2.8 \pm 0.2$ for the first, second, third and fourth wave respectively. These findings are more or less similar to the obtained results in Balady goat $(3.33 \pm 1.52,2.66 \pm 0.57$, $2.33 \pm 0.57$ and $1.66 \pm 0.57$ follicles at days of wave regression in $1,2.3$. and 4 waves respectively

\section{Conclusion}

It is concluded that ultrasonographic examinations can be satisfactory performed in our small size local breed of Balady goats. Moreover, 3-4 follicular waves could be estimated per single cycle. However, the number of growing follicles per each wave decreased dramatically from the beginning of the wave to its end either with the anovulatory or ovulatory follicles. 


\section{Conflict of interest}

The authors declare that they have no competing interest.

\section{References}

Ali, A., Dear, R. and Hussein, H. (2006): Seasonal Variation of the ovarian follicular dynamics and luteal functions of sheep in the subtropics. Theriogenology, 66: 463-469.

Costat Computer Program (1986): Version 3.03, Copyright C.C. P Software.

Coutinho, G.T.R.M, Viana, J.H.M. and Sá WF, et al. (2007): Avaliação ultra- sonográfica da dinâmica folicular e lútea emvacas da raça Guzerá. Arq Bras Med. Vet. Zootec, 59: 1089-1096.

de Castro, T., Rubianes, E., Menchaca, A. and Rivero, A. (1999): Ovarian dynamics, serum estradiol and progesterone concentrations during the interovulatory interval in goats. Theriogenology, 52: 399-411.

Driancourt, M.A. (2001): Regulation of ovarian follicular dynamics in farm animal: implications for manipulation of reproduction. Theriogenology; 55: 1211- 1239.

Duggavathi, R., Bartlewski, P.M., Barrrett, D.M., Gratton,.c, Bagu, E.T. and Rawlings, N.C. (2004): Pattern of antral follicular wave dynamics and accompanying endocrine changes in cyclic and seasonally anaestrous ewes treated with exogenous ovine follicle-stimulating hormone during the interwave interval. Biol. Reprod.; 70: 821-827.

Evan, A.C., Duffy, P., Hynes, N. and Bol, M.P. (2000): Waves of follicle development during the estrous cycle in sheep. Theriogenology; 53: 699-715.

Ginther, O.J. and Kot, K. (1994): Follicular dynamics during the ovulatory season in goats. Theriogenology, 42: 987-1001.

Ginther, O. J., Kot, K., Kulick, L. J., Martin, S. and Wiltbank, M. C. (1996): Ralationships between FSH and ovarian follicular waves during the last six months of pregnancy in cattle. J. Reprod. \& Fert. 108: 271-279.

González D. B., Santiago Moreno, A. J., García López, M., Gómez Brunet, A. and López Sebastián, A. (1994): Observación del ovario en laoveja y eficacia en la detección de folículos y cuerpos lúteos mediante ecografía transrectal. Invest. Agrar. 9, 319329.

Gonzalez D. B. , Santiago Moreno, A. J, GomezBrunet, A., Inskeep E. K., Townsend, E. C., LopezSebastian, A. (1999): Follicular dynamics during the oestrous cycle in dairy goats. Anim. Sci.; 68: 547-554.

González D. B., Diaz- Delfa, A. C., Urrutia, B., Carrizosa, J. A., López Sebastián, A. (2004): Ultrasonographic screening of the ovulatory processin goats. Small Ruminant Res. 52, 165-168.

Kähn, W .(2004): Veterinary Reproductive Ultrasonography, Special ed. Reprint from 1994. Schlütersche Verlagsgesellschaft. Hannover. pp. 189193.

Kandiel, M. M., Gen Watanabe, Mahmoud, E. A., Abou El-Roosa, Abd El Salam, I. El Azaba, Alaa, E., Abdel-Ghaffara, Gamal, A., Sosaa, Jun, Y. Lid, N., M., Kazuyoshi, T., (2011): Ovarian follicular dynamics and concentrations of ovarian and pituitary hormones during the periovulatory phase of the postpartum goats. Benha Veterinary Medical Journal Special Issue [I]: 7-13.

Kaspar, B. (1988): Beitrag zur Sonographie in der gynäkologischen Diagnostik, insbesondere zur Feststellung der Gravidität bei Schaf und Ziege. Tagungsbericht «Krankheiten der kleinen Wiederkäuer» der DVG, Gießen.

Lucy, M.C., Savio, J.D., Badinga, L., Delasota, R.L., and Thatcher, W.W. (1992): Factors that affect ovarian follicular dynamics in cattle. J. Anim. Sci. 70: 3615-3626.

Maffili, V.V.; Torres, C.A. and Bruschi, J.H. (2006): Indução do estro em cabras da raça Toggenburg com dois diferentes dispositivos intravaginais. Arquivo Brasileiro de Medicina Veterinária e Zootecnia, v.58 n.3, p.367-372.

Medan, M.S., Watanabe, G. and Sasaki and K. (2005): Follicular and hormonal dynamics during the estrous cycle in goats. J. Reprod. \& Develop., v.51 n.4, p.455463.

Mohamed S. Medan, Gen Watanabe, Kazuaki Sasaki, Sayed Sharawy, Nigel P. Groome and Kazuyoshi Taya (2003): Ovarian Dynamics and Their Associations with Peripheral Concentrations of Gonadotropins, Ovarian Steroids, and Inhibin During the Estrous Cycle in Goats. Biol. Reprod. 69, 57-63

Mohammadi, G., Hamid, K., Saad, G., Alireza, Y., and Arash, M. (2010): Ovarian follicular dynamics during 
the interovulatory interval in Najdi goats. African J. of Biotechnology Vol. 9(32), pp. 5236-5239.

Murphy, M.G., Enright, W.J., Crowe, M.A., McConnel, K., Spicer, L.J, Poland, M.P. and Roche, J.F. (1991): Effect of dietary intake on pattern of growth of dominant follicles during the estrous cycle in beef heifers. J. Reprod. Ferti.1 ,92: 333-338.

Schwarz, T., Wierzchos, E. (1999): Relation between FSH and ovarian follicular dynamics in goats during the estrous cycle. (abstr.). Theriogenology, 52: 381.

Schwarz, T. and Wierzchos, E. (2000): Relationship between FSH and ovarian follicular dynamics in goats during the estrous cycle. Theriogenology, 53: 381-381.

Simões, J., Almeida, J., Valentim, C., Baril, G., Azevedo, J., Fontes, P., And Mascarenhas, R., (2006): Follicular dynamics in Serrana goats. Anim. Reprod. Sci., (Impact Factor: 1.9). 10; 95 (1-2):16-26.

Simões, J.; Almeida, J.C.; Valentim, R. et al. (2007): Assessment of luteal function by ultrasonographic appearance and measurement of corpora lutea in goats. Anim. Reprod. Sci., V. 97, P. 36-46.

Snedecor, B.W. and Cochran,W.G. (1980): Satistical methods, 7th Ed.Iowa state Univ. Press, Ames, Iowa, USA. 